ISSN 2072-6694

www.mdpi.com/journal/cancers

Review

\title{
Predictive and Prognostic Factors in Colorectal Cancer: A Personalized Approach
}

\author{
Myutan Kulendran *, John F. Stebbing, Christopher G. Marks and Timothy A. Rockall \\ Department of Coloproctology, Royal Surrey County Hospital NHS Foundation Trust, Egerton Road, \\ Guildford, UK
}

* Author to whom correspondence should be addressed; E-Mail: myutan@ hotmail.co.uk;

Tel.: +0044-208-500-4527; Fax: +0044-208-500-4527.

Received: 23 January 2011; in revised form: 13 March 2011 / Accepted: 18 March 2011 /

Published: 29 March 2011

Abstract: It is an exciting time for all those engaged in the treatment of colorectal cancer. The advent of new therapies presents the opportunity for a personalized approach to the patient. This approach considers the complex genetic mechanisms involved in tumorigenesis in addition to classical clinicopathological staging. The potential predictive and prognostic biomarkers which have stemmed from the study of the genetic basis of colorectal cancer and therapeutics are discussed with a focus on mismatch repair status, KRAS, BRAF, 18qLOH, CIMP and TGF- $\beta$.

Keywords: predictive and prognostic factors; colorectal cancer; personalized medicine; APC; MSI; MMR; KRAS; BRAF; $18 q \mathrm{qOH}$; CIMP; TGF- $\beta$; CIN; MGMT; TP53; FOBT; vimentin; circulating tumor cells

Glossary of Abbreviations: CEA, Carcinoembryonic antigen, tumor marker; Cetuximab, Chimeric monoclonal antibody, Epidermal growth factor receptor inhibitor; CRC, Colorectal cancer; CIMP, CpG Island methylator phenotype, DNA hypermethylation characterized by epigenetic instability; CIN, Chromosomal Instability, Mutation of CIN genes increases the probability that whole chromosomes or large fractions of chromosomes are gained or lost during cell division; EGFR, Epidermal Growth Factor Receptor, cell surface receptor; KRAS, Kirsten-ras, oncogene; MMR, DNA Mismatch Repair system, functions during replication, Mismatch repair protein include: MLH1, MSH2, MSH6 and PMS2; MSI, Microsatellite Instability, secondary to defect in normal DNA repair process, Resulting in variable microsatellite lengths; MSS, Microsatellite stable tumors; 
Pantuximab, Chimeric monoclonal antibody, Epidermal growth factor receptor inhibitor; TNM, Tumor, Node, Metastasis, cancer staging system; WT-KRAS, Wild Type KRAS, non-mutated form; SNP, Single- nucleotide polymorphisms.

\section{Introduction}

The idea of personalized medicine in colorectal cancer (CRC) is becoming a reality. Research into biomarkers in CRC lags behind other tumors, such as breast and lymphoma, in which gene testing results in the use of licensed medication [1]. Extensive investigation into metastatic disease has provided a better understanding of the genetic basis of tumorgenesis and more importantly identified the significance of the EGFR pathway and KRAS mutation [2-4]. The knowledge that patients with mutated KRAS do not respond to monoclonal antibody treatment in the metastatic setting has been an important step forward in attempting to tailor medication to the individual. This has led to careful genotyping of patients and identifying those with wild type-KRAS (WT-KRAS) for cetuximab and panitumumab therapy, leading to a reduction in chemotherapy toxicity and cost-effectiveness [5]. This finding has led to a host of other genetic biomarkers being studied in an aim to identify alterations that allow us to predict the prognosis of individual tumors and their response to therapy.

Clinicopathological staging determines treatment and plays a key role in selecting patients for clinical trials. The most robust determinants of prognosis include [6]:

-Local involvement (pT category of TNM);

-Regional lymph node metastasis (pN category of TNM staging);

-Lymphovascular invasion;

-Positive surgical margin;

-Pre-operative elevation of CEA;

-High tumor grade;

-Tumor budding.

In addition, patients who present with bowel perforation and obstruction are likely to have a poorer outcome because of locally advanced disease [7]. Although clinicopathological parameters determine the management of patients in the multi-disciplinary team setting they are not reliable predictors of treatment outcome. It is hoped the development of genetic biomarkers can be used in combination with clinicopathological staging. The current thinking behind CRC tumorgenesis and potential biomarkers that have been identified in the synthesis of this model will be discussed.

\section{Adenoma-Carcinoma Sequence}

Discovery of genetic alterations in the pathogenesis of CRC are beginning to piece together how they may relate to the Fearson and Volgelstein Model [8]. Epigenetic alterations are thought to be precursor events in tumor progression through the serrated, alternate Vogelstein model [9]. It is believed that CRC may arise from at least three interlinked mechanisms. Chromosomal Instability (CIN) is the most commonly found in CRC accounting for up to $80 \%$ of cases [10]. The classic 
Vogelstein report, which describes the step by step mutational process starting from a small adenoma to invasive cancer, is the theoretical basis for our understanding of the CIN pathway [11]. CRC progresses through activating mutations in oncogenes or deactivation of tumor suppressor genes. This leads to a selection of clonal tumor cells which continue to divide through a growth advantage. Inactivating mutations in APC and activating mutations in KRAS are thought to be early changes in the Vogelstein sequence. Mutations in p53 and TGF- $\beta$ have been described as late changes in tumorgenesis. An understanding of the CIN pathways has been pivotal in investigating potential predictive and prognostic markers in CRC. Unlike MSI tumors, the mechanism underlying CIN is poorly understood. CIN tumors are characterized by aneuploidy, multiple chromosomal rearrangements and an accumulation of somatic mutations [12] (Figure 1). CIN tumors have a poor prognosis compared to MSI tumors [10].

Figure 1. The modified Fearson and Volgenstein Model. Colorectal cancer (CRC) progression can occur through either the chromosomal instability (CIN) or microsatellite instability (MSI) pathway. Early adenomatous changes are secondary to loss of APC. KRAS loss initiates the formation of larger adenomas in the CIN pathway followed by $18 \mathrm{qLOH}$. Mutations in TP53 are a late change. Sporadic MSI tumors are commonly part of the serrated neoplasia pathway and BRAF mutations are more common finding.

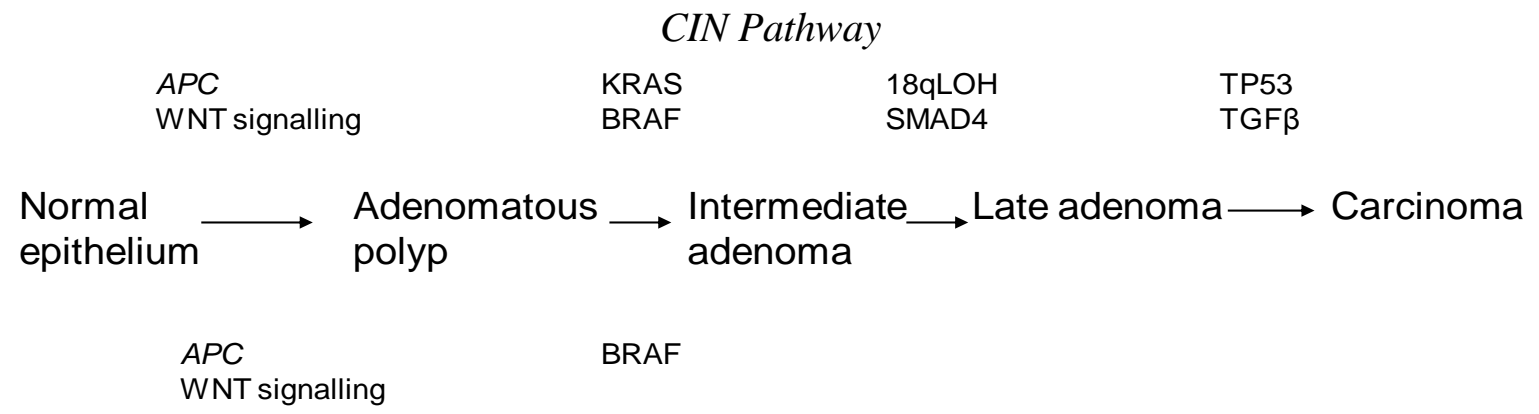

MSI

The loss of heterozygosity on the long arm of chromosome $18(18 \mathrm{qLOH})$ is the most common genetic alteration in colorectal cancer. SMAD4 and deleted in Colorectal Cancer (DCC) are two important tumor suppressor genes found on the long are of chromosome 18 [13,14]. Studies have shown that $18 \mathrm{qLOH}$ is an indicator of poor prognosis in early stage CRC, which has not been proven by multi-variate studies against other biomarkers, making $18 \mathrm{qLOH}$ an unlikely independent prognostic marker [15]. Furthermore 18qLOH has associations with CIN [16].

Deletion of SMAD4 by 18qLOH results in tumorgensis via the TGF $\beta$ pathway [17]. The loss of SMAD4 is a poor prognostic indicator. The retention of the SMAD4 diploidy results in a three-fold higher benefit from 5-Fluorouracil therapy (5-FU) chemotherapy [18].

Mutations in the tumor suppressor gene TP53 are found in almost half of CRC [19]. Mutations in different domains of the gene lead to a variable prognosis [20-24]. TP53 mutations are found more commonly in distal CRC $[25,26]$. Proximal tumors found to have mutations in TP53 were more likely to exhibit lymphatic invasion and be more responsive to 5-FU therapy. Mutation in exon 5 of the TP53 gene is associated with a poorer outcome [27]. Individuals with wild type TP53 have a superior 
survival rate with 5-FU therapy in rectal cancer [19]. At present there is no strong data to support the role of TP53 as a prognostic or predictive marker in CRC.

\subsection{MSI}

The most widely studied and understood genomic instability is Microsatellite Instability (MSI). MSI are found in $15 \%$ of CRC and is characterized by the inactivation of the Mismatch Repair Genes (MMR) [28,29]. MSI are the cause of hereditary CRC but are also found in sporadic cancers. In sporadic cases of MSI the MMR gene activity is silenced by promoter methylation of the hMLH1 gene [30,31]. Several genes affected by MSI have been identified including TGF- $\beta$ [32], those encoding regulation of cell proliferation, cell cycle or apoptosis and DNA repair [33]. MSI represents a unique pathway for tumor development that does not involve loss of heterozygosity [34].

In Hereditary Non-Polyposis Coli Syndrome (HNPCC) a germline mutation in MMR occurs in an autosomal dominant fashion leading to MSI [30]. Although most research into MSI has focused on familial CRC only 3\% of all CRC come from HNPCC and most MSI CRC are sporadic [35]. Macroscopically sporadic MSI tumors are characteristically proximally located, poorly differentiated and of a mucinous histology with lymphocytic infiltration [36]. The genetic properties of sporadic CRC include bialleleic methylation of the MLHI promoter, absence of MLH1 and PM2 protein and frequent mutations in BRAF [37].

MSI is a potential predictor of treatment response to 5-FU and prognosis of disease when used in conjunction with TNM staging [38]. Cultured CRC cells with intact MMR activity were more significantly sensitive to therapeutic concentration of 5-FU than DNA MMR deficient cells [39]. In vitro studies on CRC cells that do not express MLH1 has shown that exposure to the demethylating agent 5-azacytidine led to the expression of MLH1 and sensitivity to 5-FU [40].

MSI can be divided into MSI-High (MSI-H) tumors, which are MMR deficient, and MSI-Low (MSI-L) tumors, found to be proficient in MMR genes [41]. In the National Surgical Adjuvant Breast and Bowel Project (NSABP), CRC patients were divided into a non-treatment arm and an adjuvant chemotherapy arm and the MSI status was determined. The prognostic analyses showed increased recurrence-free survival (RFS) for MSI-H patients versus MSS/MSI-L patients $(P=10)$, but showed no difference in overall survival (OS; $P=67)$.

Retrospective studies on resected stage II and stage III CRC have shown that MSI-H tumors have a better prognosis compared to MSI-L tumors when not subjected to adjuvant chemotherapy [42]. In vitro studies have hypothesized that defective DNA MMR leads to 5-FU therapy resistance in CRC [43]. The Quick and Simple and Reliable Study (QUASAR) has shown that 5-FU therapy is beneficial in stage II CRC with the Overall Survival (OS) ranging between 1-5\% [6]. In contrast the International Multi-centre Pooled Analysis of Colon Cancer Trials (IMPACT) B2 study did not show any advantage from combined 5-FU/leucovarin over surgery alone in Stage II CRC [44]. Furthermore 5-FU therapy may in fact be detrimental in this sub-group. Similar finding have been found in MSI-H, Stage III CRC in vivo [41]. There has been little evidence for the benefit of chemotherapy in patients with MSI CRC. The addition of topoisomerase-I inhibitor irinotecan in the chemotherapeutic regimen leads to increased survival times in patients with MSI tumors $[45,46]$. 
More recently, a new entity of MSI has been has been described. The signature is termed elevated microsatellite alterations at selected tetranucleotide repeats (EMAST). EMAST can be found in up to $60 \%$ of sporadic CRC and co-exists with MSI-H and MSI-L tumors. EMAST is thought to occur due to down regulation of MSH-3 [47].

It can be argued that MSI status should be routinely determined as part of staging CRC. At present there is no general consensus for deciding on who should receive adjuvant chemotherapy in stage II disease. It is unclear if all patients with stage II disease will benefit from adjuvant chemotherapy, MSI status may be a candidate for determining suitability for adjuvant chemotherapy.

The addition of oxaliplatin with infusional 5-FU in FOLFOX therapy has demonstrated a significant improvement in three-year disease free survival in patients with stage II, node negative disease. There is currently no published data with regard to the interaction between oxaliplatin and MSI status. The prognostic significance of MSI is unquestionable but it is essential to know more about CRC genetic status than MSI alone, these potential biomarkers shall be discussed below.

\subsection{KRAS}

Kirsten-ras (KRAS) mutations are the most widely studied and promising biomarker for treatment strategies in CRC. It is a downstream mediator of the EGFR signaling pathway [16]. KRAS mutations are an early event in the adenoma-carcinoma sequence and are found in 40\% of CRC [8]. KRAS mutations are thought to be a poor prognostic marker in CRC [48]. There is, however, conflicting evidence. The KRAS in-colorectal-cancer collaborative group (RASCAL II) study has shown that a glycine to valine mutation on codon 12 of the KRAS gene is aggressive in patients with Duke's C CRC [49]. It was associated with a 50\% increased risk of relapse or death in this group of patients.

KRAS mutations are maintained in metastatic CRC [50,51]. Mutant KRAS exhibits resistance to monoclonal antibody (mAb) therapy [3,4]. This phenomenon has been studied extensively in metastatic disease. Randomized controlled trials have shown no survival benefit from adding cetuximab to chemotherapy in unselected patients [52-54]. The large, randomized, phase II Oxaliplatin and Cetuximab in First-Line Treatment of CRC (OPUS) trial has indicated that it may be harmful to add cetuximab to those with mutated KRAS [55]. A Phase III trial (the CRYSTAL study) confirms that a combination of cetuximab and FOLFIRI statistically improves response rate and PFS in the WT-KRAS population [52]. Current practice involves genotyping patients with metastatic CRC prior to starting mAb therapy. The European Health Committee for human medicinal products has recommended the use of panitumumab monotherapy and cetuximab therapy in patients with metastatic CRC found to have WT-KRAS in the primary tumor [56].

PIK3CA is a downstream effector of the KRAS pathway and is down regulated by the tumorsuppressor gene PTEN. PIK3CA is a potential marker of resistance to mAb therapy [57].

\subsection{BRAF}

BRAF mutations are found in 10\% of CRC. Most B-Raf mutations involve the V600E amino acid substitution, resulting in constitutive activation of the MEK-ERK signaling pathway. They are mutually exclusive of KRAS mutations and are thus a candidate for an independent biomarker for CRC [58]. Studies on WT-KRAS tumors treated by either a combination of chemotherapy and cetuximab 
or cetuximab alone have shown that progression free survival (PFS) and OS were significantly better among patient without mutated BRAF (WT-BRAF) [59]. The presence of BRAF mutations in an MSI tumor makes a hereditary cause unlikely [60,61]. Therefore the strategy for identifying individuals with Lynch syndrome is a two tier approach. The initial test involves immunohistochemistry testing for MMR protein in tissue and MSI DNA testing. Individuals found to be $\mathrm{MSI}^{+}$with a loss of MMR proteins (MSH2, MHS6 and PMS2) undergo further DNA testing for the appropriate gene. Patients who are $\mathrm{MSI}^{+}$with either a loss of MLH1 or no MMR protein loss undergo Tier 2 screening. This consists of BRAF mutational analysis at V600E and MLH1 promoter methylation, both of which are associated with sporadic CRC [62,63].

At present, inhibitors of BRAF have been tested in vitro and the inhibitor PLX4032 has been shown to potentiate the anti-proliferative action of 5-FU therapy [64]. At present, further in vivo studies investigating the action of the tyrosine kinase inhibitor (BAY 43-9006) and cetuximab in the metastatic setting are being undertaken. Tyrosine kinase inhibitors are believed to restore sensitivity to mAb therapy in mutant-BRAF cell lines [4]. They show promise as potential treatment methods. However deliverability and costs of treatment are yet to be evaluated.

\subsection{CIMP}

DNA methylation is recognized as one of the most common gene alterations in human tumors including CRC [65]. A subset of CRC exhibit promoter methylation at multiple sites and are referred to as the $\mathrm{CpG}$ island methylator phenotype (CIMP) [66,67]. The CIMP is observed in $30 \%$ of CRC. This has been hypothesis as an early contributor to CRC progression [68]. Both hyper and hypo-methylation of DNA play a role in CRC tumorogenesis [69]. Before the entity of CIMP was identified, CRC was classified into either MSI or CIN in origin. It now apparent that come tumors are neither MSI or CIN and that hypermethylation of DNA is a common finding in CRC [70,71]. Sporadic MSI tumors are secondary to CIMP related silencing of the MMR gene MLH1 [63,72]. The difficulty producing a standardized marker and the unclear distinction between the CIMP tumors and sporadic MSI tumors has meant that the clinical importance of CIMP tumors is difficult to quantify. CIMP can be divided into CIMP-High (CIMP-H) and CIMP-Low (CIMP-L) groups [70]. The CIMP-H tumors are associated with the BRAF mutation whereas CIMP-L are associated with KRAS mutations [73-75]. CIMP-H tumors found to be MSI positive and haboring the BRAF mutation have a good prognosis [59]. However MSI negative tumors which are positive for CIMP and the BRAF mutation hold a poor prognosis [76]. Global hypomethylation of DNA is associated with CIN tumors and may also confer a poor prognosis [77,78].

In vitro it is possible to demethylate some promoters using the DNA methyltransferase inhibitor 5 -azacytidine although remethylation occurs on removal of the agent. The search for a targeted and more prolonged acting agent may be of therapeutic use [79].

Gene expression arrays comparing CRC tissue with adjacent normal mucosa are identifying and validating novel methylated genes that may in the future be candidate prognostic biomarkers [80-85]. Aberrant DNA methylation can be detected from a variety of samples including blood, stool and tissue, giving it a wide variety of clinical uses [86-88].

CIMP positivity in CRC was thought to be a significant independent predictor of survival benefit from 5-FU chemotherapy [89]. However, recent studies have failed to prove this for Stage II-III CRC [90]. 
It would be ideal to combine the molecular classification of CRC with DNA methylation status to predict treatment response and prognosis. The role of epigenetic therapy has been proven to be effective in treating hematological malignancies and is likely to extend to CRC in the future [91].

\section{5. $M G M T$}

The DNA repair gene 06-methylguanine-DNA methyletransferase (MGMT) is often methylated in CRC [92]. Sporadic cancer is thought to arise from regions of cells with field change. MGMT has been detected in healthy tissue surrounding tumor cells [93]. It has been hypothesized that MGMT field change may represent a preneoplastic state for the development of MSI tumors. In support of this there is an increase in promoter DNA methylation as tumors progress through the adenoma sequence with increasing malignant potential. MGMT may serve as a prognostic marker for CRC, however recent immunohistochemistry studies have failed to show any association of MGMT promoter methylation or loss as a prognostic biomarker in CRC [94].

\subsection{Early Detection of $C R C$}

The most evaluated screening tool for the detection of CRC is the biennel Faecal Occult Blood Test (FOBT). The sensitivity of the FOBT for important neoplasms remains low, between 30-50\% [95]. Those who test positive are invited for colonoscopy which detects and allows excision of adenomas reducing the incidence of cancers by $16 \%[96,97]$. The early detection of cancers allows for treatment of less advanced disease. An alternative to FOBT would be fecal DNA based tests. Such tests that detect DNA mutations are complicated, expensive and also sensitive to adenomas [98].

In the USA, stool based methylated Vimentin (m-Vimentib) is currently available commercially. The vimentin gene, which is transcriptionally silent in normal colorectal epithelial cells, becomes methylated in colorectal cancers [99]. The development of more sensitive technology enables absolute quantification of the number of methylated molecules in a sample, and detection of m-Vimentin in plasma may act as a potential biomarker or tumor marker [100].

Circulating tumor cells is FDA approved for patient prognosis in metastatic colorectal cancer [101-103] and may in the future act as a predictive biomarker as well as give an indication of cell dissemination during surgery [104].

\section{Discussion}

New evidence highlighting the variation in altered pathways leading to CRC has provided a modified version of the classic Vogelstein and Fearson model. At present it is thought that there are three parallel pathways which give rise to sporadic colorectal cancer with distinct clinicopathological features.

MSI tumors are associated with the serrated neoplasia pathway and frequently carry the BRAF mutation [105]. These tumors are often CIMP positive. CIN tumors are activated by biallelic loss of APC and p53 mutation classically forming tubular adenomas of the distal colon. The CIMP pathway is heterogenous in nature; again there is a strong association with the BRAF mutation. The prognostic value of promoter hypermethylation is still under investigation. The role of BRAF mutation in V600E 
and MSI already play a role in determining a hereditary cause for CRC, their usefulness in sporadic CRC is now beginning to merge.

Identification of KRAS and subsequent testing for this marker has opened the doors for personalized medicine and further research into other potential biomarkers. MAb therapy targeting the EGFR pathway has shown great efficacy in the treatment of patients with metastatic CRC. However, antiEGFR therapy is only useful for a fraction of patients, making it essential to look for alternative pathways and inhibitors. There is a vast array of new targets being studied as possible new biomarkers, some of which are being tested clinically to patients.

The commercially available OncoTypeDx is a RT-PCR gene assay, which detects 12 validated genes in CRC and produces a recurrence score for Stage II and II disease after resection. The assay is not predictive of treatment response. The seven prognostic genes include three stromal: FAP, INHBA and BGN; three cell type genes: Ki-67, c-myc and MYBL2 and GADD45B [106].

The evolution of CRC progression from an adenomatous polyp to invasive cancer and metastasis may be dependent on protein markers [107]. Among those studied, cell surface markers show promise for further development. Cell surface markers are necessary for cell-cell adhesion and communication. The role of stroma-derived biomarkers, tumor-associated macrophages, infiltrating lymphocytes and small transmembrane proteins have been described [108]. Despite the discovery of a wide range of protein biomarkers for $\mathrm{CRC}$, the translation into clinical practice is challenging due to the difficulty in detecting and characterizing low abundance proteins in complex mixtures and the validation of biomarkers in clinical practice. Issues with regard to validity arise from the multitude of marker assessment methods, feasibility of obtaining the specimens, reliability and reproducibility of the assay and the costs involved with assessing the marker status on every patient [109].

An ideal way to assess tumor status would be a serum marker. Serum markers allow for a minimally invasive method of CRC screening that could easily integrated into regular health checks. Six serum biomarkers have been studied using ELISA. CEA showed the best sensitivity at 95\%, with a specificity of $43.9 \%$ followed by seprase (42.4\% sensitivity), CYFRA 21-1 (35.5\%), osteopntin (30.2\%), ferritin $(23.9 \%)$ and anti-p53 (20.0\%). When used in combination the sensitivity of these markers was equal to fecal immunohistochemical testing [110].

Other novel markers for further investigation include Single-Nucleotide Polymorphisms (SNPs). The study of SNPs has identified variants in SMAD7 associated with CRC. The SNPs rs4939827, rs 1295317 and rs4464148 have shown evidence of an association between genotype and risk in three independent CRC case-controlled series by allelic-specific PCR. The locus on SMAD 7 may contribute up to $15 \%$ of CRC [111].

\section{Conclusions}

The revolution of personalized medicine not only benefits the patient by reducing drug toxicity and optimizing patient outcome but can also reduce costs for an already burdened health system. In the future, personalized medicine means that therapeutic regimens will be tailored more and more to the individual. The era of personalized medicine opens a very exciting time for the management of colorectal cancer and in combination with minimally invasive surgical techniques will benefit the patient greatly. 


\section{Acknowledgements}

The leading author would like to express their deepest gratitude and warmth appreciation to the Royal Surrey Hospital for the vast research opportunities made available to me.

\section{References}

1. Van't Veer, L.; Dai, H.; van de Vijver, M.J.; He, Y.D.; Hart, A.A.; Mao, M.; Peterse, H.L.; van der Kooy, K.; Marton, M.J.; Witteveen, A.T.; et al. Gene expression profiling predicts clinical outcome of breast cancer. Nature 2002, 415, 530-536.

2. Allegra, C.J.; Jessup, J.M.; Somerfield, M.R.; Hamilton, S.R.; Hammond, E.H.; Hayes, D.F.; McAllister, P.K.; Morton, R.F.; Schilsky, R.L. American Society of Clinical Oncology provisional clinical opinion: Testing for KRAS gene mutations in patients with metastatic colorectal carcinoma to predict response to anti-epidermal growth factor receptor monoclonal antibody therapy. J. Clin. Oncol. 2009, 27, 2091-2096.

3. Karapetis, C.S.; Khambata-Ford, S.; Jonker, D.J.; O'Callaghan, C.J.; Tu, D.; Tebbutt, N.C.; Simes, R.J.; Chalchal, H.; Shapiro, J.D.; Robitaille, S.; et al. K-ras mutations and benefit from cetuximab in advanced colorectal cancer. N. Eng. J. Med. 2008, 359, 1757-1765.

4. Siena, S.; Sartore-Bianchi, A.; Di Nicolantonio, F.; Balfour, J.; Bardelli, A. Biomarkers predicting clinical outcomeof epidermal growth factor receptor-targeted therapy in metastatic colorectal cancer. J. Nat. Cancer Inst. 2009,101, 1308-1324.

5. National Comprehensive Cancer Network (NCCN) Clinical Practice Guidelines in Oncology: Colon CancerV.2.2010, 2010, http://www.nccn.org/professionals/physician_gls/PDF/colon.pdf/.

6. Compton, C.C.; Fielding, L.P.; Burgart, L.J.; Conley, B.; Cooper, H.S.; Hamilton, S.R.; Hammond, M.E.; Henson, D.E.; Hutter, R.V.; Nagle, R.B.; et al. Prognostic factors in colorectal cancer. College of American pathologists consensus statement, 1999. Arch. Pathol. Lab. Med. 2000, 124, 979-994.

7. Steinberg, S.M.; Barkin, J.S.; Kaplan, R.S.; Stablein, D.M. Prognostic indicators of colon tumours. The Gastrointestinal Tumour Study Group experience. Cancer 1986, 57, 1866-1870.

8. Vogelstein, B.; Fearson, E.R.; Hamilton, S.R.; Kern, S.E.; Preisinger, A.C.; Leppert, M.; Nakamura, Y.; White, R.; Smits, A.M.; Bos, J.L. Genetic alterations during colorectal-tumor development. N. Engl. J. Med. 1988, 319, 525-532.

9. Leggett, B.; Whitehall, V. Role of the serrated pathway in colorectal pathogenesis. Gastroenterology 2010, 138, 2088-2100.

10. Grady, W.M.; Carethers, J.M. Genomic and epigenetic instability in colorectal cancer pathogenesis. Gastroenterology 2008, 135, 1079-1099.

11. Kinzler, K.W.; Vogelstein, B. Colorectal tumors. In The Genetic Basis of Human Cancer; Vogelstein, B., Kinzler, K.W., Eds.; McGraw-Hill: New York, NY, USA, 1998; pp. 565-587.

12. Kane, M.F.; Loda, M.; Gaida, G.M.; Lipman, J.; Mishra, R.; Goldman, H.; Jessup, J.M.; Kolodner, R. Methylation of the hMLH1 promoter correlates with lack of expression og hMLH1 in sporadic colon tumours and mismatch repair-defective human tumor cell lines. Cancer Res. 1997, 57, 808-811. 
13. Carethers, J.M.; Hawn, M.T.; Greenson, J.K.; Hitchcock, C.L.; Boland, C.R. Prognostic significance of allelic lost at chromosome 18q21 for stage II colorectal cancer. Gastroenterology 1998, 114, 1188-1195.

14. Alhopuro, P.; Alazzouzi, H.; Sammalkorpi, H.; Dávalos, V.; Salovaara, R.; Hemminki, A.; Järvinen, H.; Mecklin, J.P.; Schwartz, S., Jr.; Aaltonen, L.A.; Arango, D. SMAD4 levels and response 5-fluoouracil in colorectal cancer. Clin. Cancer Res. 2005, 11, 6311-6316.

15. Rowan, A.; Halford, S.; Gaasenbeek, M.; Kemp, Z.; Sieber, O.; Volikos, E.; Douglas, E.; Fiegler, H.; Carter, N.; Talbot, I.; Silver, A.; et al. Refining molecular analysis in the pathway of colorectal carcinogenesis. Clin. Gastroenterol. Hepatol. 2005, 3, 1115-1123.

16. Olschwang, S.; Hamelin, R.; Laurent-Puig, P.; Thuille, B.; De Rycke, Y.; Li, Y.J.; Muzeau, F.; Girodet, J.; Salmon, R.J.; Thomas, G. Alternative genetic pathways of colorectal carcinogenesis. Proc. Natl. Acad. Sci. USA 1997, 94, 12122-12127.

17. Alberts, J.; Lewis, R.; Roberts, W. The molecular basis of cancer cell behaviour. In Molecular Biology of the Cell, 5th ed.; Garland Science, Taylor and Francis Group: New York, NY, USA, 2008; pp. 1251-1252.

18. Boulay, J.L.; Mild, G.; Lowy, A.; Reuter, J.; Lagrange, M.; Terracciano, L.; Laffer, U.; Herrmann, R.; Rochlitz, C. SMAD4 is a predictive marker for 5-fluoraucil-based chemotherapy in patients with colorectal cancer. Br. J. Cancer 2002, 87, 630-634.

19. Iacopetta, B. TP53 mutation in colorectal cancer. Hum. Mutat. 2003, 21, 271-276.

20. Borresen-Dale, A.; Lothe, R.A.; Meling, G.I.; Hainaut, P.; Rognum, T.O.; Skovlund, E. TP53 and long-term prognosis in colorectal cancer: Mutations in the L3 Zinc-binding predict poor survival. Clin. Cancer Res. 1998, 4, 203-210.

21. Iniesta, P.; Vega, F.J.; Caldes, T.; Massa, M.; de Juan, C.; Cerdán, F.J.; Sánchez, A.; López, J.A.; Torres, A.J.; Balibrea, J.L.; et al. p53 exon 7 mutations as a predictor of poor prognosis in patients with colorectal cancer. Cancer Lett. 1998, 130, 153-160.

22. Samowitz, W.S.; Curtin, K.; Ma, K.N.; Edwards, S.; Schaffer, D.; Leppert, M.F.; Slattery, M.L. Prognostic significance of p53 mutations in colon cancer at the population level. Int. J. Cancer 2002, 99, 597-602.

23. Jernval, P.; Makinen, M.; Kerttunen, T.; Mäkelä, J.; Vihko, P. Conserved region mutations of the p53gene are concentrated in distal colorectal cancers. Int. J. Cancer 1997, 74, 97-101.

24. Russo, A.; Migliavacca, M.; Zanna, I.; Valerio, M.R.; Latteri, M.A.; Grassi, N.; Pantuso, G.; Salerno, S.; Dardanoni, G.; Albanese, I.; et al. p53 mutations in L3-loop zinc binding domain, DNA-ploidy and $\mathrm{S}$ phase fraction are independent prognostic indicators in colorectal cancer: A prospective study with a 5 year follow-up. Cancer Epidem. Biomarker. Prev. 2002, 11, 1322-1331.

25. Hamelin, R.; Laurent-Puig, P.; Olschwang, S.; Jego, N.; Asselain, B.; Remvikos, Y.; Girodet, J.; Salmon, R.J.; Thomas, G. Association of p53 mutations with short survival in colorectal cancer. Gastroenterology 1994, 106, 42-48.

26. Goh, H.S.; Elnatan, J.; Low, C.H.; Smith, D.R. p53 point mutation and survival in colorectal cancer patients: Effect of disease dissemination and tumour location. Int. J. Oncol. 1999, 15, 491-498. 
27. Russo, A.; Bazan, V.; Iacopetta, B.; Kerr, D.; Soussi, T.; Gebbia, N. The TP53 colorectal cancer international collaborative study on the prognostic and predicitve significance of p53 mutation: Influence of tumour site, type of mutation and adjuvant treatment. J. Clin. Oncol. 2005, 23, 7518-7528.

28. Shibata, D.; Pienado, M.A.; Ionov, Y.; Malkhosyan, S.; Perucho, M. Genomic instability in repeated sequences is an early somatic event in colorectal tumorigenesis that persists after transformation. Nat. Genet. 1994, 6, 273-281.

29. Aaltonen, L.A.; Peltomaki, P.; Mecklin, J.P.; Järvinen, H.; Jass, J.R.; Green, J.S.; Lynch, H.T.; Watson, P.; Tallqvist, G.; Juhola, M. Replication errors in benign and malignant tumors from hereditary nonpolyposis colorectal cancer patients. Cancer Res. 1994, 54, 1645-1648.

30. Grady, W.M. Genomic instability and colon cancer. Cancer Metast. Rev. 2004, 23, 11-27.

31. Walther, A.; Houlston, R.; Tomlinson, I. Association between chromosomal instability and prognosis in colorectal cancer: A meta-analysis. Gut 2008, 57, 941-950.

32. Markowitz, S.; Wang, J.; Myeroff, L.; Parsons, R.; Sun, L.; Lutterbaugh, J.; Fan, R.S.; Zborowska, E.; Kinzler, K.W.; Vogelstein, B. Inactivation of the type II TGF-beta receptor in colon cancer cells with microsatellite instability. Science 1995, 268, 1336-1338.

33. Duval, A.; Hamelin, R. Mutations at coding repeat sequences in mismatch repair-deficient human cancers: toward a new concept of target genes for instability. Cancer Res. 2002, 62, 2447-2454.

34. Thibodeau, S.N.; Bren, G.; Schaid, D. Microsatellite instability in cancer of the proximal colon. Science 1993, 260, 816-819.

35. Hampel, H.; Frankel, W.L.; Martin, E.; Arnold, M.; Khanduja, K.; Kuebler, P.; Nakagawa, H.; Sotamaa, K.; Prior, T.W.; Westman, J.; et al. Screening for the Lynch syndrome (hereditary nonpolyposis colorectal cancer). N. Engl. J. Med. 2005, 352, 1851-1860.

36. Young, J.; Simms, L.A.; Biden, K.G.; Wynter, C.; Whitehall, V.; Karamatic, R.; George, J.; Goldblatt, J.; Walpole, I.; Robin, S.A.; et al. Features of colorectal cancers with high-level microsatellite instability occurring in familial and sporadic settings: Parallel pathways of tumorigenesis. Am. J. Pathol. 2001, 159, 2107-2116.

37. Wang, L.; Cunningham, J.M.; Winters, J.L.; Guenther, J.C.; French, A.J.; Boardman, L.A.; Burgart, L.J.; McDonnell, S.K.; Schaid, D.J.; Thibodeau, S.N. BRAF mutations in colon cancer are not likely attributable to defective DNA mismatch repair. Cancer Res. 2003, 63, 5209-5212.

38. George, P.; Kim, L.H.; Colangelo, H.; Samuel, W.; Soonmyung, P.; Ilan, R.K.; Norman, W.; Carmen, J.A. Prognostic and predictive roles of high-degree microsatellite instability in colon cancer: A national cancer institute-national surgical adjuvant breast and bowel project collaborative study. J. Clin. Oncol. 2007, 25, 767-772.

39. Carethers, J.M.; Chauhan, D.P.; Fink, D.; Nebel, S.; Bresalier, R.S.; Howell, S.B.; Boland, C.R. Mismatch repair proficiency and in vitro response to 5-fluorouracil. Gastroenterology 1999, 117, 123-131.

40. Arnold, C.N.; Goel, A.; Boland, C.R. Role of hMLH1 promoter hypermethylation in drug resistance to 5-fluorouracil in colorectal cancer cell lines. Int. J. Cancer 2003, 106, 66-73.

41. Pawlik, T.M.; Raut, C.P.; Rodriguez-Bigas, M.A. Colorectal carcinogenesis: MSI-H versus MSI-L. Disease Marker. 2004, 20, 199-206. 
42. Ribic, C.M.; Sargent, D.J.; Moore, M.J.; Thibodeau, S.N.; French, A.J.; Goldberg, R.M.; Hamilton, S.R.; Laurent-Puig, P.; Gryfe, R.; Shepherd, L.E.; et al. Tumor microsatelliteinstability status as a predictor of benefit from fluorouracil-based adjuvant chemotherapy for colon cancer. N. Engl. J. Med. 2003, 349, 247-257.

43. Jo, W.; Carethers, J.M. Chemotherapeutic implications in microsatellite unstable colorectal cancer. Cancer Biomark. 2006, 2, 51-60.

44. International multicentre pooled analysis of B2 colon cancer trials (IMPACT B2) investigators. Efficacy of adjuvant fluorouracil and folinic acid in B2 colon cancer. J. Clin. Oncol. 1999, 17, 1356-1363.

45. Fallik, D.; Borrini, F.; Boige, V.; Viguier, J.; Jacob, S.; Miquel, C.; Sabourin, J.C.; Ducreux, M.; Praz, F. Microsatellite instability is a predictive factor of the tumor response to irinotecan in patients with advanced colorectal cancer. Cancer Res. 2003, 63, 5738-5744.

46. Bertagnolli, M.M.; Niedzwiecki, D.; Compton, C.C.; Hahn, H.P.; Hall, M.; Damas, B.; Jewell, S.D.; Mayer, R.J.; Goldberg, R.M.; Saltz, L.B.; et al. Microsatellite instability predicts improved response to adjuvant therapy with irinotecan, fluorouracil, and leucovorin in stage III colon cancer: Cancer and Leukemia Group B Protocol 89803. J. Clin. Oncol. 2009, 27, 1814-1821.

47. Ahrendt, S.A.; Decker, P.A.; Doffek, K.; Wang, B.; Xu, L.; Demeure, M.J.; Jen, J.; Sidransky, D. Microsatellite instability at selected tetranucleotide repeats is associated with p53 mutations in non-small cell lung cancer. Cancer Res. 2000, 60, 2488-2491.

48. Richman, S.D.; Seymour, M.T.; Chambers, M.T.; Elliott, F.; Daly, C.L.; Meade, A.M.; Taylor, G.; Barrett, J.H.; Quirke, P. KRAS and BRAF mutations in advanced colorectal cancer are associated with poor prognosis but do not preclude benefit from oxaliplatin or irinotecan: Results from the MRC FOCUS trial. J. Clin. Oncol. 2009, 27, 5931-5937.

49. Andreyev, H.J.; Norman, A.R.; Cunningham, D.; Oates, J.; Dix, B.R.; Iacopetta, B.J.; Young, J; Walsh, T.; Ward, R.; Hawkins, N.; et al. Kirsten ras mutations in patients with colorectal cancer: the 'RASCAL II' study. Br. J. Cancer 2001, 5, 692-696.

50. Artale, S.; Satore-Bianchi, A.; Veronese, S.M.; Gambi, V.; Sarnataro, C.S.; Gambacorta, M.; Lauricella, C.; Siena, S. Mutations of KRAS and BRAF in primary and matched metastatic sites of colorectal cancer. J. Clin. Oncol. 2008, 26, 4217-4219.

51. Zauber, P.; Sabbath-Solitare, M.; Marotta, S.P.; Bishop, D.T. Molecular changes in the Ki-RAS and APC genes in primary colorectal carcinoma and synchronous metastases compared with the findings in accompanying adenomas. Mol. Pathol. 2003, 56, 137-140.

52. Van Cutsem, E.; Kohne, C.H.; Hitre, E.; Zaluski, J.; Chang Chien, C.R.; Makhson, A.; D’Haens, G.; Pintér, T.; Lim, R.; Bodoky, G.; et al. Cetuximab and chemotherapy as initial treatment for metastatic colorectal cancer. N. Engl. J. Med. 2009, 360, 1408-1417.

53. Tabernero, J.; Cervantes, A.; Ciardiello, F. Correlation of Efficacy to KRAS Status (wt versus mut) in Patients (pts) with Metastatic Colorectal Cancer $(m C R C)$, Treated with Weekly $(q 1 w)$ and $q 2 w$ Schedules of Cetuximab Combined with FOLFIRI. Proceedings of ASCO Gastrointestinal Cancers Symposium, Orlando, Florida, January 2008. 
54. Bokemeyer, C.; Bondarenko, I.; Makhson, A.; Hartmann, J.T.; Aparicio, J.; de Braud, F.; Donea, S.; Ludwig, H.; Schuch, G.; Stroh, C.; et al. Fluorouracil, leucovorin and oxaliplatin with and without cetuximab in the first-line treatment of metastatic colorectal cancer. J. Clin. Oncol. 2009, 27, 663-671.

55. Bokemeyer, C.; Bondarenko, I.; Makhson, A. Cetuximab Plus 5-FU/FA/Oxaliplatin (FOLFOX-4) versus FOLFOX-4 in the First-Line Treatment of Metastatic Colorectal Cancer (mCRC): OPUS, A Randomized Phase II Study. Proceedings of the American Society of Clinical Oncology Conference, Chicago, IL, USA, 2007.

56. Europeans Medicines Agency. Committee for Medicinal Products for Human Use May 2008 Plenary Monthly report.2008. http://www.emea.europe.eu/pdfs/human/press/pr.27923508en.pdf/.

57. Danielson, S.A.; Lind, G.E.; Bjornslett, M.; Meling, G.I.; Rognum, T.O.; Heim, S.; Lothe, R.A. Novel mutations of the suppressor gene PTEN in colorectal carcinoma stratified by microsatellite instability- and TP53 mutation status. Hum. Mutat. 2008, 29, E252-E262.

58. Rajagopalan, H.; Bardelli, A.; Lengauer, C.; Kinzler, K.W.; Vogelstein, B.; Velculescu, V.E. Tumorigenesis: RAF/RAS oncogenes and mismatch-repair status. Nature 2002, 418, 934.

59. Di Nicolantonio, F.; Martini, M.; Molinari, F.; Sartore-Bianchi, A.; Arena, S.; Saletti, P.; De Dosso, S.; Mazzucchelli, L.; Frattini, M.; Siena, S.; et al. Wild-type BRAF is required for response to panitumumab or cetuximab in metastatic colorectal cancer. J. Clin. Oncol. 2008, 26, 5705-5712.

60. Domingo, E.; Laiho, P.; Ollikainen, M.; Pinto, M.; Wang, L.; French, A.J.; Westra, J.; Frebourg, T.; Espín, E.; Armengol, M.; et al. BRAF screening as a low-cost effective strategy for simplifying HNPCC genetic testing. J. Med. Genet. 2004, 41, 664-668.

61. Weisenberger, D.J.; Siegmund, K.D.; Campan, M.; Young, J.; Long, T.I.; Faasse, M.A.; Kang, G.H.; Widschwendter, M.; Weener, D.; Buchanan, D.; et al. CpG island methylator phenotype underlies sporadic microsatellite instability and is tightly associated with the BRAF mutation in colorectal cancer. Nat. Genet 2006. 38, 787-793.

62. Bettstetter, M.; Dechant, S.; Ruemmele, P.; Grabowski, M.; Keller, G.; Holinski-Feder, E.; Hartmann, A.; Hofstaedter, F.; Dietmaier, W. Distinction of hereditary nonpolyposis colorectal cancer and sporadic microsatellite-unstable colorectal cancer through quantification of MLH1 methylation by real time PCR. Clin. Res. 2007, 13, 3221-3228.

63. Zhang, L. Immunohistochemistry versus microsatellite instability testing for screening colorectal cancer patients at risk for hereditary nonpolyposis colorectal cancer syndrome. Part II. The utility of microsatellite instability testing. J. Mol. Diagn. 2008, 10, 301-307.

64. Kolinsky, K.D.; Su, F.; Bollag, G.; Lee, R.; Packman, K.; Schostack, K.; Heimbrook, D.; Kohles, J.; Higgins, B. Efficacy of PLX4032, A Selective ${ }^{{ }^{V 60 E}}$ B-Raf Inhibitor, as Monotherapy or in Combination with Capecitabine \pm Bevacizumab in a Colorectal Cancer Xenograft Model. Proceedings of the 2009 Gastrointestinal Cancers Symposium, San Francisco, CA, January 1517, 2009, Abstract 632.

65. Laird, P.W. Cancer epigenetics. Hum. Mol. Genet. 2005, 14, R65-R76.

66. Issa, J.P. CpG island methylator phenotype in cancer. Nat. Rev. Cancer 2004, 4, 988-993. 
67. Toyota, M.; Ahuja, N.; Ohe-Toyota, M.; Herman, J.G.; Baylin, S.; Issa, J.P. CpG island methylation in colorectal cancer. Proc. Natl. Acad. Sci. USA 1999, 96, 8681-8686.

68. Matsuzaki, K.; Deng G, Tanaka, H.; Kakar, S.; Miura, S.; Kim, Y.S. The relationship between global methylation level, loss of heterozygosity and microsatellite instability in sporadic colorectal cancer. Clin. Cancer Res. 2005, 11, 8564-8569.

69. Rodriguez, J.; Frigola, J.; Vendrell, E.; Risques, R.A.; Fraga, M.F.; Morales, C.; Moreno, V.; Esteller, M.; Capellà, G.; Ribas, M.; et al. Chromosomal instability correlates with genome wide DNA demethylation in human primary colorectal cancer. Cancer Res. 2006, 66, 8462-9468.

70. Georgiades, I.B.; Curtis, L.J.; Morris, R.M.; Bord, C.C.; Wyllie, A.H. Heterogeneity studies identify a subset of sporadic colorectal cancers without evidence for chromosomal or microsatellite instability. Oncogene 1999, 18, 7933-7940.

71. Barault, L.; Charon-Barra, C.; Jooste, V.; de la Vega, M.F.; Martin, L.; Roignot, P.; Rat, P; Bouvier, A.M.; Laurent-Puig, P.; Faivre, J.; et al. Hypermethylator phenotype in sporadic colon cancer: study on a population-based series of 582 cases. Cancer Res. 2008, 68, 8541-8546.

72. Jass, J.R. Serrated adenoma of the colorectum and the DNA methylator phenotype. Nat. Clin. Pract. Oncol. 2005, 2, 398-405.

73. Lumbomierski, N.; Plotz, G.; Wormek, M.; Engels, K.; Kriener, S.; Trojan, J.; Jungling, B.; Zeuzem, S.; Raedle, J. BRAF mutations in colorectal carcinoma suggests two entities of microsatellite-unstable tumours. Cancers 2005, 104, 952-961.

74. Ogino, S.; Kawasaki, T.; Kirkner, G.J.; Loda, M.; Fuchs, C. CpG island methylator phenotypelow (CIMP-low) in colorectal cancer: possible associations with male sex and KRAS mutations. J. Mol. Diagn. 2006, 8, 582-588.

75. Samowitz, W.S.; Sweeney, C.; Herrick, J.; Albertsen, H.; Levin, T.R.; Murtaugh, M.A.; Wolff, R.K.; Slattery, M.L. Poor survival associated with the BRAF V600E mutation in microsatellitestable colon cancers. Cancers Res. 2005, 65, 6063-6069.

76. Russo, A.; Bazan, V.; Iacopetta, B.; Kerr, D.; Soussi, T.; Gebbia, N. The TP53 colorectal cancer international collaborative study on the prognostic and predictive significance of p53 mutation: Influence of tumour site, type of mutation and adjuvant treatment. J. Clin. Oncol. 2005, 23, 7518-7528.

77. Matsuzaki, K.; Deng, G.; Tanaka, H.; Kakar, S.; Miura, S.; Kim, Y.S. The relationship between global methylation level, loss of heterozygosity and microsatellite instabilityin sporadic colorectal cancer. Clin. Cancer Res. 2005, 11, 8564-8569.

78. Rodriguez, J.; Frigola, J.; Vendrell, E.; Risques, R.A.; Fraga, M.F.; Morales, C.; Moreno, V.; Esteller, M.; Capellà, G.; Ribas, M.; Peinado, M.A. Chromosomal instability correlates with genome wide DNA demethylation in human primary colorectal cancer. Cancer Res. 2006, 66, $8462-9458$.

79. Kondo, Y.; Issa, J.P. Epigenetic changes in colorectal cancer. Cancer Metast. Rev. 2004, 23, 29-39.

80. Cunningham, J.M.; Christensen, E.R.; Tester, D.J.; Kim, C.Y.; Roche, P.C.; Burgart, L.J.; Thibodeau, S.N. Hypermethylation of the hMLH1 promoter in colon cancer with microsatellite instability. Cancer Res. 1998, 58, 3455-3460. 
81. Herman, J.G.; Umar, A.; Polyak, K.; Graff, J.R.; Ahuja, N.; Issa, J.P.; Markowitz, S.; Willson, J.K.; Hamilton, S.R.; Kinzler, K.W.; et al. Incidence and functional consequences of hMLH1 promoter hypermethylation in colorectal carcinoma. Proc. Natl. Acad. Sci. USA 1998, 95, 6870-6875.

82. Wheeler, J.M.; Beck, N.E.; Kim, H.C.; Tomlinson, I.P.; Mortensen, N.J.; Bodmer, W.F. Mechanisms of inactivation of mismatch repair genes in human colorectal cancer cell lines: The redominant role of hMLH1. Proc. Natl. Acad. Sci. USA 1999, 96, 10296-10301.

83. Kane, M.F.; Loda, M.; Gaida, G.M.; Lipman, J.; Mishra, R.; Goldman, H.; Jessup, J.M.; Kolodner, R. Methylation of the hMLH1 promoter correlates with lack of expression of hMLH1 in sporadic colon tumors and mismatch repair-defective human tumor cell lines. Cancer Res. 1997, 57, 808-811.

84. Veigl, M.L.; Kasturi, L.; Olechnowicz, J.; Ma, A.H.; Lutterbaugh, J.D.; Periyasamy, S.; Li, G.M.; Drummond, J.; Modrich, P.L.; Sedwick, W.D.; Markowitz, S.D. Biallelic inactivation of hMLH1 by epigenetic gene silencing, a novel mechanism causing human MSI cancers. Proc. Natl. Acad. Sci. USA 1998, 95, 8698-8702.

85. Suzuki, H.; Watkins, D.N.; Jair, K.W.; Schuebel, K.E.; Markowitz, S.D.; Chen, W.D.; Pretlow, T.P.; Yang, B.; Akiyama, Y.; Van Engeland, M.; et al. Epigenetic inactivation of SFRP genes allows constitutive WNT signaling in colorectal cancer. Nat. Genet. 2004, 36, 417-422.

86. Chen, W.D.; Han, Z.J.; Skoletsky, J.; Olson, J.; Sah, J.; Myeroff, L.; Platzer, P.; Lu, S.; Dawson, D.; Willis, J.; et al. Detection in fecal DNA of colon cancer-specific methylation of the nonexpressed vimentin gene. J. Nat. Cancer Inst. 2005, 97, 1124-1132.

87. Petko, Z.; Ghiassi, M.; Shuber, A.; Gorham, J.; Smalley, W.; Washington, M.K.; Schultenover, S.; Gautam, S.; Markowitz, S.D.; Grady, W.M. Aberrantly methylated CDKN2A, MGMT, and MLH1 in colon polyps and in fecal DNA from patients with colorectal polyps. Clin. Cancer Res. 2005, 11, 1203-1209.

88. Grady, W.M.; Rajput, A.; Lutterbaugh, J.D.; Markowitz, S.D. Detection of aberrantly methylated hMLH1 promoter DNA in the serum of patients with microsatellite unstable colon cancer. Cancer Res. 2001, 61, 900-902.

89. Rijnsoever, M.; Elsaleh, H.; Joseph, D.; McCaul, K.; Iacopetta, B. CpG island methylator phenotype is an independent predictor of survival benefit from 5-fluorouracil in stage II colorectal cancer. Clin. Cancer Res. 2003, 9, 2898-2903.

90. Jover, R.; Nguyen, T.P.; Pérez-Carbonell, L.; Zapater, P.; Payá, A.; Alenda, C.; Rojas, E.; Cubiella, J.; Balaguer, F.; Morillas, J.D.; et al. 5-Fluorouracil adjuvant chemotherapy does not increase survival in patients with $\mathrm{CpG}$ island methylator phenotype colorectal cancer. Gastroenterology 2010, 140, 1174-1181.

91. Griffiths, E.A.; Gore, S.D. DNA methyltransferase and histone deacetylase inhibitors in the treatment of myelodysplastic syndromes. Semin. Hematol. 2008, 45, 23-30.

92. Ogino, S.; Hazra Tranah, G.J.; Kirkner, G.J.; Kawasaki, T.; Nosho, K.; Ohnishi, M.; Suemoto, Y.; Meyerhardt, J.A.; Hunter, D.J.; Fuchs, C.S. MGMT germline polymorphism is associated with somatic MGMT promoter methylation and gene silencing in colorectal cancer. Carcinogenesis 2007, 28, 1985-1990. 
93. Shen, L.; Kondo, Y.; Rosner, G.L.; Xiao, L.; Hernandez, N.S.; Vilaythong, J.; Houlihan, P.S.; Krouse, R.S.; Prasad, A.R.; Einspahr, J.G.; et al. MGMT promoter methylation and field defect in sporadic colorectal cancer. J. Nat. Cancer Inst. 2005, 21, 1317-1379.

94. Shima, K.; Morikawa, T.; Baba, Y.; Suzuki, M.; Yamauchi, M.; Hayashi, M.; Giovannucci, E.; Fuchs, C.S.; Ogino, S. MGMT promoter methylation, loss of expression and prognosis in 855 colorectal cancers. Cancer Causes Control 2011, 22, 301-309.

95. American College of Physicians. Suggested technique for fecal occult blood testing and interpretation in colorectal cancer screening. Ann. Int. Med. 1997, 126, 808-810.

96. Mandel, J.S.; Bond, J.H.; Church, T.R.; Snover, D.C.; Bradley, G.M.; Schuman, L.M.; Ederer, F. Reducing mortality from colorectal cancer by screening for fecal occult blood. N. Engl. J. Med. 1993, 328, 1365-1371.

97. Mandel, J.S.; Church, T.R.; Ederer, F.; Bond, J.H. Colorectal cancer mortality: Effectiveness of biennial screening for fecal occult blood. J. Nat. Cancer Inst. 1999, 91, 434-437.

98. Kim, Y.H.; Lee, H.C.; Kim, S.Y.; Yeom, Y.I.; Ryu, K.J.; Min, B.H.; Kim, D.H.; Son, H.J.; Rhee, P.L.; Kim, J.J.; et al. Epigenomic analysis of aberrantly methylated genes in colorectal cancer identifies genes commonly affected by epigenetic alterations. Ann Surg Oncol. 2011, doi: 10.1245/s10434-011-1573-y.

99. Brenner, D.E.; Rennert, G. Fecal DNA biomarkers for the detection of colorectal neoplasia: Attractive, but is it feasible? J. Nat. Cancer Inst. 2005, 97, 1107-1109.

100. Li, M.; Chen, W.D.; Papadopoulos, N.; Goodman, S.N.; Bjerregaard, N.C.; Laurberg, S.; Levin, B.; Juhl, H.; Arber, N.; Moinova, H.; et al. Sensitive digital quantification of DNA methylation in clinical samples. Nat. Biotechnol. 2009, 27, 853-863.

101. Cohen, S.J.; Punt, C.J.A.; Iannotti, N.; Saidman, B.H.; Sabbath, K.D.; Gabrail, N.Y.; Picus, J.; Morse, M.A.; Mitchell, E.; Miller, M.C.; et al. Prognostic significance of circulating tumour cells in patients with metastatic colorectal cancer. Ann. Oncol. 2009, 20, 1223-1229.

102. Cohen, S.J.; Punt, C.J.A.; Iannotti, N.; Saidman, B.H.; Sabbath, K.D.; Gabrail, N.Y.; Picus, J.; Morse, M.; Mitchell, E.; Miller, M.C.; et al. Relationship of circulating tumour cells to tumour response, progression-free survival, and overall survival in patients with metastatic colorectal cancer. J. Clin. Oncol. 2008, 26, 3213-3221.

103. Tol, J.; Koopman, M.; Miller, M.C.; Tibbe, A.; Cats, A.; Creemers, G.J.; Vos, A.H.; Nagtegaal, I.D.; Terstappen, L.W.; Punt, C.J. Circulating tumour cells early predict progression-free and overall survival in advanced colorectal cancer patients treated with chemotherapy and targeted agents. Ann. Oncol. 2009, 21, 1006-1012.

104. Uen, Y.H.; Lu, C.Y.; Tsai, H.L.; Yu, F.J.; Huang, M.Y.; Cheng, T.L.; Lin, S.R.; Wang, J.Y. Persistent presence of postoperative circulating tumour cells is a poor prognostic factor for patients with stage I-III colorectal cancer after curative resection. Ann. Surg. Oncol. 2008, 15, 2120-2128.

105. Harvey, N.T.; Ruszkiewicz, A. Serrated neoplasia of the colorectum. World J. Gastroenterol. 2007, 28, 3792-3798. 
106. O’Connell, M.J.; Lavery, I.C.; Gray, R.G.; Quirke, P.; Kerr, D.J.; Lopatin, M.; Yothers, G.A.; Lee, M.; Clark-Langone, K.; Wolmark, N. Comparison of Molecular and Pathologic Features of Stage II and Stage III Colon Cancer in Four Large Studies Conducted for Development of the 12Gene Colon Cancer Recurrenced Score. Proceeding of 2010 Gastrointestinal Cancer Symposium, Orlando, Florida, January 22-24, 2010, Abstract 280.

107. McAllister, S.S.; Weinberg, R.A. Tumor-host interactions: A far-reaching relationship. J. Clin. Oncol. 2010, 28, 4022-4028.

108. Belov, L.; Zhou, J.; Richard, I. Christopherson, cell surface markers in colorectal cancer prognosis. Int. J. Mol. Sci. 2011, 12, 78-113.

109. Mandrekar, S.J.; Sargent, D.J. Clinical trial designs for predictive biomarker validation: theoretical considerations and practical challenges. J. Clin. Oncol. 2009, 24, 4027-4034.

110. Wild, N.; Andres, H.; Rollinger, W.; Krause, F.; Dilba, P.; Tacke, M.; Karl, J. A combination of serum markers for the early detection of colorectal cancer. Clin. Cancer Res. 2010, 24, 6111-6121.

111. Broderick, P.; Carvajal-Carmona, L.; Pittman, A.M.; Webb, E.; Howarth, K.; Rowan, A.; Lubbe, S.; Spain, S.; Sullivan, K.; Fielding, S.; et al. A genome-wide association study shows that common alleles of SMAD7 influence colorectal cancer risk. Nat. Genet. 2007, 11, 1315-1317.

(C) 2011 by the authors; licensee MDPI, Basel, Switzerland. This article is an open access article distributed under the terms and conditions of the Creative Commons Attribution license (http://creativecommons.org/licenses/by/3.0/). 